\title{
Mediodorsal Thalamus Plays a Critical Role in the Development of Limbic Motor Seizures
}

\author{
Robert M. Cassidy and Karen Gale \\ Interdisciplinary Program in Neuroscience and Department of Pharmacology, Georgetown University Medical Center, \\ Washington, DC 20007
}

\begin{abstract}
Limbic motor seizures in animals, analogous to complex partial seizures in humans, result in a consistent activation of the mediodorsal thalamus (MD) and, with prolonged seizures, damage to $M D$. This study examined the functional role of $M D$ in focally evoked limbic motor seizures in the rat. GABA- and glutamate (Glu)-mediated synaptic transmissions in MD were evaluated for an influence on seizures evoked from area tempestas (AT), a discrete epileptogenic site in the rostral piriform cortex.

A GABA $A_{A}$ receptor agonist, Glu receptor antagonists, or a GABA-elevating agent were focally microinfused into MD before evoking seizures by focal application of bicuculline methiodide into the ipsilateral AT. Focal pretreatment of MD with the GABA $_{A}$ agonist muscimol $(190 \mathrm{pmol})$ protected against seizures evoked from AT. Seizure protection was also obtained with the focal application of 2,3-dihydroxy-6-nitro-7-sulfamoyl-benzo(F)quinoxaline (NBQX) $(500 \mathrm{pmol})$, an antagonist of the AMPA subtype of Glu receptors, into MD. In contrast, focal pretreat-
\end{abstract}

Area tempestas (AT) is a functionally defined, discrete epileptogenic site deep within the anterior piriform cortex, which has been identified in the rat and monkey (Piredda and Gale, 1985; Gale and Dubach, 1993). In the rat, unilateral microinjection of picomole amounts of GABA receptor antagonists or glutamate (Glu) receptor agonists elicits synchronous bilateral electrographic and motor seizures, characterized by facial and forelimb clonus with rearing and loss of balance (Piredda and Gale, 1985); this type of seizure, often referred to as "limbic motor seizure", is analogous to secondarily generalized complex partial seizures in humans (McNamara et al., 1993). Two neurochemical substrates within AT are crucial to seizure genesis: inhibitory GABAergic transmission and excitatory glutamatergic transmission. A tonic balance between excitatory glutamatergic input and inhibitory GABAergic input exists within AT, and the unilateral disruption of this balance in favor of excitation triggers seizures. Accordingly, focal injection of bicuculline, a $\mathrm{GABA}_{\mathrm{A}}$ receptor antagonist, removes the endogenous inhibitory control in AT and allows the endogenous excitatory drive to evoke limbic motor

Received June 9, 1998; revised Aug. 5, 1998; accepted Aug. 7, 1998.

This work was supported by National Institutes of Health Grants T32HD07549, NS28130, and NS20576. We thank Dr. Francesco Fornai and David Dybdal for helpful discussions throughout the course of these studies and Laura Williams for help with the preparation of this manuscript.

Correspondence should be addressed to Dr. Karen Gale, Department of Pharmacology, Georgetown University Medical Center, 3900 Reservoir Road N.W., Washington, DC 20007.

Copyright (C) 1998 Society for Neuroscience $\quad 0270-6474 / 98 / 189002-08 \$ 05.00 / 0$ ment of MD with a competitive antagonist of the NMDA receptor 2-amino-7-phosphonoheptanoic acid (500 pmol) did not attenuate seizures. The anticonvulsant effects achieved with intra-MD injections of muscimol and NBQX were site-specific, because no seizure protection was obtained with injections placed $2 \mathrm{~mm}$ ventral or lateral to MD. Prolonged seizure protection was obtained following GABA elevation in MD after the application of the GABA transaminase inhibitor vigabatrin (194 nmol). These results suggest the following: (1) MD is a critical participant in the generation of seizures elicited focally from piriform cortex; (2) transmission via AMPA receptors, but not NMDA receptors, in MD regulates limbic seizure propagation; and (3) a GABA-mediated system exists within MD, the enhancement of which protects against focally evoked limbic motor seizures.

Key words: area tempestas; piriform cortex; bicuculline; GABA; glutamate; vigabatrin

seizures (Piredda and Gale, 1986a). In the rat, the local blockade of either NMDA or AMPA receptors protects against seizure activity elicited by focal bicuculline, indicating that both subtypes of Glu receptor are necessary for seizure initiation from AT (Piredda and Gale, 1986a; Tortorella et al., 1997).

Studies mapping increases in metabolic activity, as indicated by the uptake of $\left[{ }^{14} \mathrm{C}\right] 2$-deoxyglucose $(2 \mathrm{DG})$, have found that seizures evoked from anterior piriform cortex produce a marked increase in cellular metabolism in a specific set of forebrain regions. These areas include olfactory bulbs, posterior piriform cortex, perirhinal cortex, amygdala, entorhinal cortex, and mediodorsal thalamus (MD) (see Fig. 1) (Gale, 1993; White and Price, 1993). Similarly, a time course of immunohistochemical localization of heat shock protein during ictal activity elicited from unilateral injections of bicuculline into AT demonstrates that this cellular stress marker is expressed preferentially in the ipsilateral amygdala, posterior piriform cortex, perirhinal cortex, and MD (Shimosaka et al., 1992). Interestingly, perirhinal cortex (Tortorella et al., 1997) and posterior piriform cortex (Halonen et al., 1994) appear to serve as important relays in the seizurepropagating network, based on the fact that inhibition within these regions impedes seizure generation. The anatomical connections of MD suggest that it may represent another critical component of the limbic seizure network. Because MD receives input from numerous components of the limbic system, including the piriform and rhinal cortices, it may integrate input from these multiple components and link them with cingulate cortex and with orbitofrontal cortex, with which MD has reciprocal connec- 

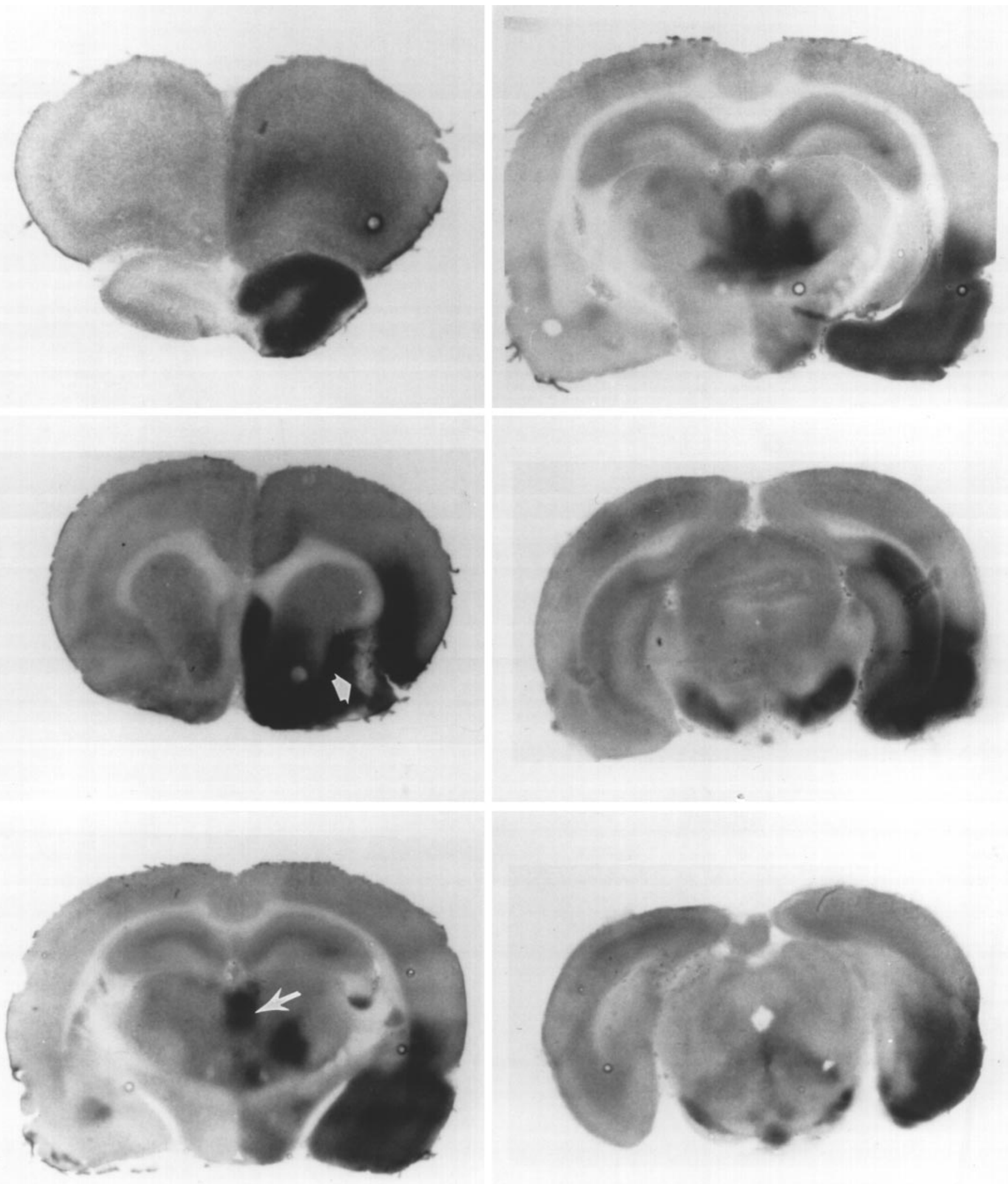

Figure 1. Pictures of autoradiographs showing accumulation of 2DG (dark areas) in coronal sections of rat brain. Bicuculline methiodide was injected $15 \mathrm{~min}$ before the intraperitoneal injection of 2DG (18 mCi into $250 \mathrm{gm}$ rats). Rats were anesthetized and perfused $1 \mathrm{hr}$ after injection of bicuculline. Arrow in left column, middle row, points to AT microinfusion site. Arrow in left column, bottom row, points to MD. 

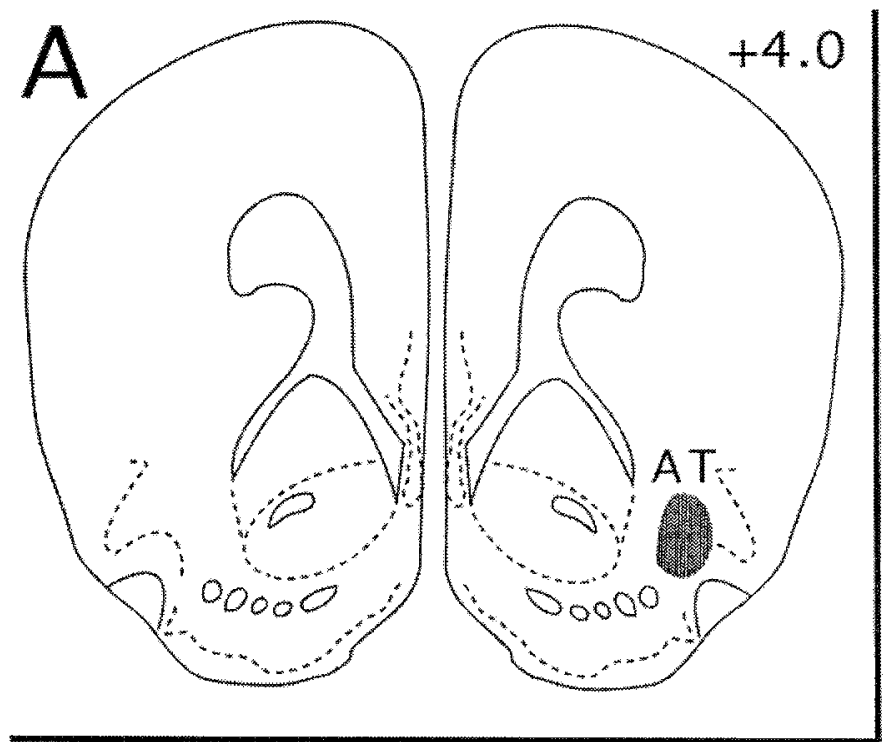

B

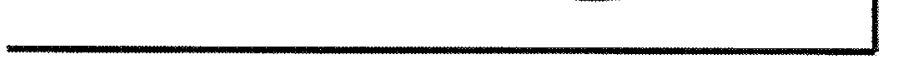

$-1.6$

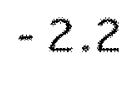

$-1.8$
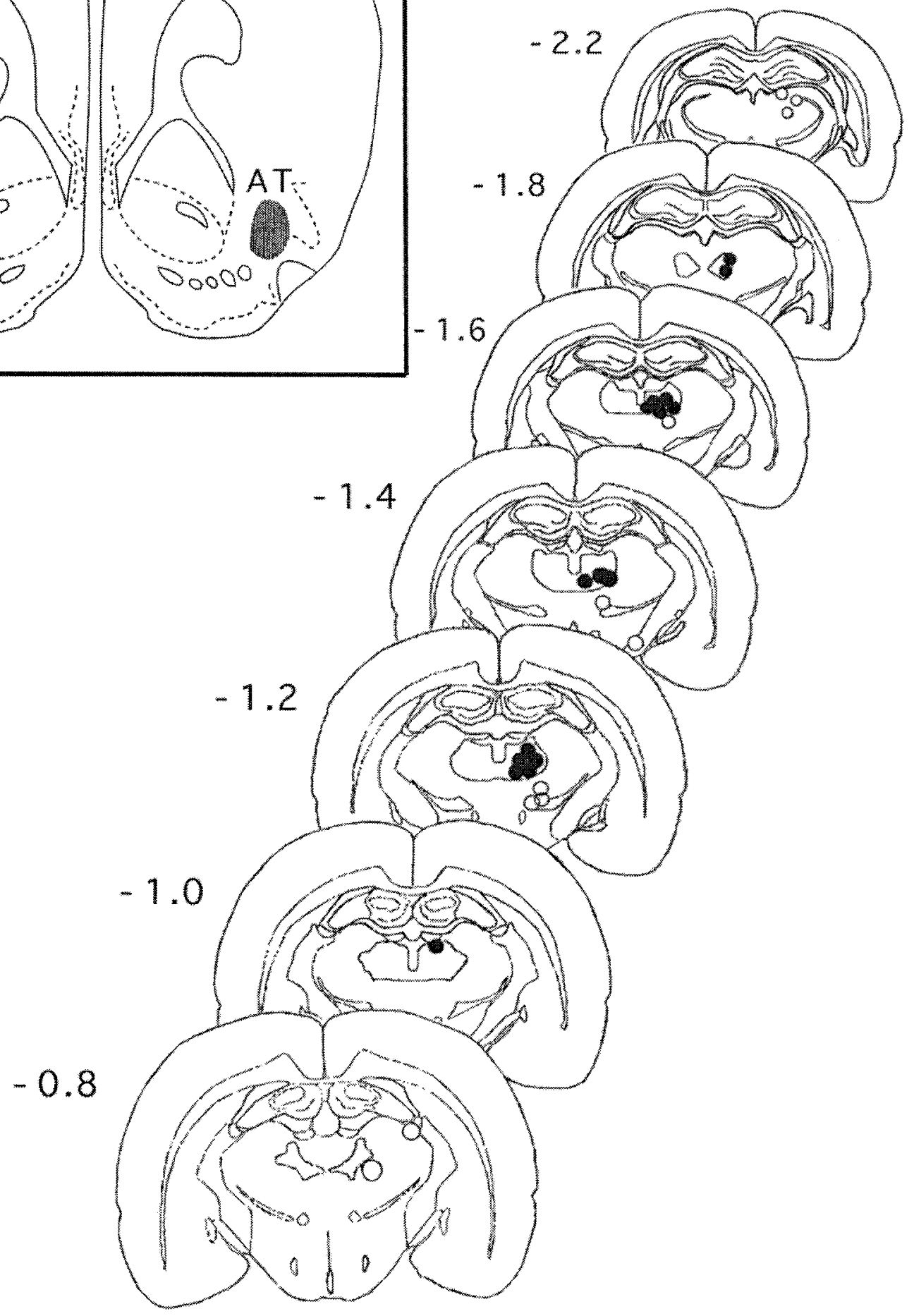

Figure 2. Sites of focal microinfusions. $A$, Coronal representation depicting area of microinfusions within AT (shaded area). B, Drawings of coronal sections depicting location of microinf usions of muscimol or NBQX within MD from which seizure protection was obtained ( filled circles). Open circles represent sites where no seizure protection was obtained from these two drugs. Numbers indicate anteroposterior distance from bregma in millimeters. 


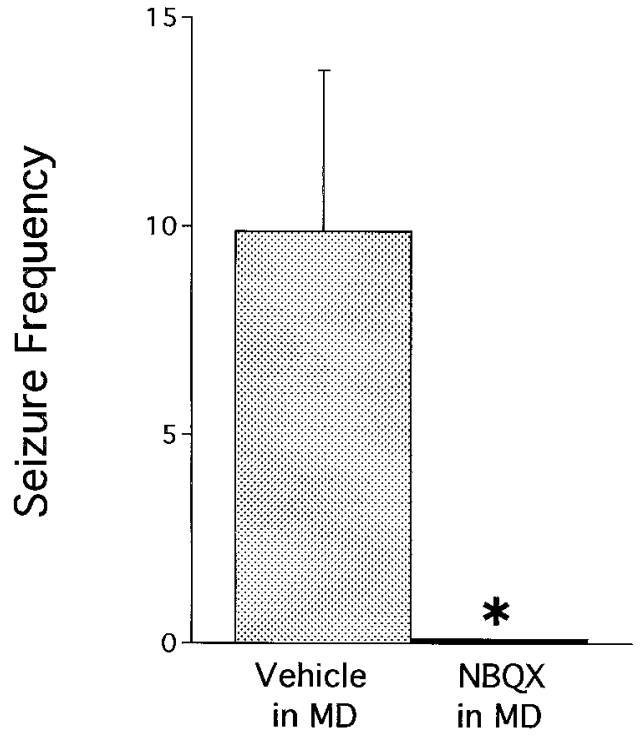

Figure 3. Effect of focal microinf usion of an AMPA receptor antagonist in MD. NBQX (500 pmol; $n=9)$ was unilaterally microinf used into MD $5 \mathrm{~min}$ before microinfusion of bicuculline $(118 \mathrm{pmol})$ into the ipsilateral AT. Difference from controls, ${ }^{*} p<0.05$ ( $t$ test).

tions (Russchen et al., 1987; Giguere and Goldman-Rakic, 1988; Gower, 1989; Carmichael and Price, 1995).

Furthermore, studies analyzing patterns of neurodegeneration after seizures have reported that pronounced neuronal death occurs bilaterally in MD as a result of continuous generalized seizure activity evoked from AT (Shimosaka et al., 1992), systemic administration of pilocarpine (Turski et al., 1986), and in humans experiencing prolonged idiopathic hemiconvulsions (Mori et al., 1992). These findings raise the possibility that seizure-induced pathology in MD may contribute to short-term and/or long-term consequences of prolonged or repeated seizures.

In view of the above evidence that MD is a target of seizure activity triggered from piriform cortex, we investigated the functional role of MD in limbic motor seizures. In the present study, we tested the hypothesis that MD contributes to the propagation of limbic seizures evoked from the piriform cortex. To accomplish this, we examined the effects of focal inhibition of MD on seizures evoked from AT.

\section{MATERIALS AND METHODS}

Animals. All experiments were performed on male Sprague Dawley albino rats (250-350 gm; Harlan Labs, Walkersville, MD). The animals were housed in groups of three to four per cage under environmentally controlled conditions ( $12 \mathrm{hr}$ light/dark cycle, lights on between 8:00 A.M. and 8:00 P.M.; ambient temperature $23^{\circ} \pm 1^{\circ} \mathrm{C}$ ), with food and water provided ad libitum. All experiments were conducted during the light cycle in awake freely moving animals and strictly conformed to all guidelines set forth by the Georgetown University Animal Care and Use Committee.

Surgery. Rats were anesthetized with Equithesin ( $2.7 \mathrm{ml} / \mathrm{kg}$, i.p.) and placed in a Kopf stereotaxic apparatus. Two 22-gauge stainless steel guide cannulas $(0.71 \mathrm{~mm}$ external diameter), one directed at the left AT and one directed at the left MD, were then stereotaxically implanted and fixed to the skull with dental acrylic and stainless steel jeweler's screws.

According to the deGroot coordinate system (Pellegrino et al., 1973), the coordinates used for the final injection sites, with the incisor bar 5 $\mathrm{mm}$ above the interaural line, were as follows: AT, $4 \mathrm{~mm}$ anterior to bregma; $3.5 \mathrm{~mm}$ lateral to midline; and $6.5 \mathrm{~mm}$ ventral to dura; MD, 1.2 $\mathrm{mm}$ posterior to bregma; $1.0 \mathrm{~mm}$ lateral to midline; and $6.2 \mathrm{~mm}$ ventral to dura (see Fig. $2 A, B$ for AT and MD sites, respectively).
Drugs. 2-Amino-7-phosphonoheptanoic acid (AP-7) (Research Biochemicals, Natick, MA) was dissolved in a small volume ( $<10 \%$ of final volume) of $1 \mathrm{~N} \mathrm{NaOH}$, the $\mathrm{pH}$ was adjusted to 7.4 with $\mathrm{H}_{3} \mathrm{PO}_{4}$, and the solution was then diluted with distilled deionized water to a concentration of $0.5 \mathrm{mg} / \mathrm{ml}$. A dose of $500 \mathrm{pmol}$ of AP-7 was injected in a volume of $225 \mathrm{nl}$ over a duration of $5 \mathrm{~min}$. Bicuculline methiodide (Sigma, Saint Louis, MO) was dissolved in saline at a concentration of $0.5 \mathrm{mg} / \mathrm{ml} ; 118$ pmol in $120 \mathrm{nl}$ was infused over $2 \mathrm{~min} 40 \mathrm{sec}$. Equithesin (used for anesthetic) was made by combining chloral hydrate $(4.3 \%)$, pentobarbital $(0.9 \%)$, and $\mathrm{MgSO}_{4}(2.1 \%)$ in propylene glycol-ethanol-water. Vigabatrin (Marion Merrel Dow, Cincinatti, $\mathrm{OH}$ ) was dissolved in saline at a concentration of $100 \mathrm{mg} / \mathrm{ml} ; 194 \mathrm{nmol}$ in $250 \mathrm{nl}$ was infused over a duration of 5 min $33 \mathrm{sec}$. Muscimol (Natural Products Research Chemicals) was dissolved in saline at a concentration of $0.1 \mathrm{mg} / \mathrm{ml} ; 190 \mathrm{pmol}$ in $240 \mathrm{nl}$ was infused over a period of $5 \mathrm{~min} 20 \mathrm{sec}$. The sodium salt 2,3-dihydroxy-6-nitro-7-sulfamoyl-benzo(F)-quinoxaline (NBQX) (NovoNordisk, Malov, Denmark) was dissolved in saline at a concentration of $1.0 \mathrm{mg} / \mathrm{ml} ; 500 \mathrm{pmol}$ in a volume of $159 \mathrm{nl}$ was infused over a duration of $3 \mathrm{~min} 45 \mathrm{sec}$.

Experimental procedures. After a postoperative recovery period of at least $48 \mathrm{hr}$, each animal received a unilateral microinfusion of a convulsant dose of bicuculline methiodide $(118 \mathrm{pmol})$ in AT with or without pharmacological pretreatment of MD. Glu receptor antagonists (AP-7 or $\mathrm{NBQX}$ ), a $\mathrm{GABA}_{\mathrm{A}}$ receptor agonist (muscimol), or an irreversible inhibitor of GABA transaminase (vigabatrin) were focally microinf used in the ipsilateral MD before the unilateral application of bicuculline to AT. For each infusion, a 28-gauge internal cannula $(0.36 \mathrm{~mm}$ external diameter) was inserted through the guide cannula while the rat was gently handheld, and the drugs were then infused at a rate of $45 \mathrm{nl} / \mathrm{min}$. The internal cannula was connected via polyethylene tubing to a $10 \mu \mathrm{l}$ Hamilton syringe (Hamilton Co., Reno, NV) driven by a Sage infusion pump. After each infusion, the internal cannula was left in place for 1 min to ensure proper delivery of drug solution.

All animals were observed for convulsive activity for at least $2 \mathrm{hr}$ after the final infusion of bicuculline in AT. Seizure severity was evaluated using the following scoring system modified from Racine (1972): 0.5, facial clonus; 1 , myoclonus of the contralateral forelimb; 2 , bilateral forelimb clonus (with or without facial and jaw clonus) lasting $<15 \mathrm{sec}$; 3 , bilateral forelimb clonus lasting $>15 \mathrm{sec}$; 4 , rearing in addition to bilateral forelimb clonus; 5 , rearing and loss of balance in addition to bilateral forelimb clonus.

Histology. Brains were sectioned $(50 \mu \mathrm{m})$ on a freezing-stage microtome. Injection sites were then verified in cresyl violet-stained sections viewed under light microscopy. Rats in which cannula placements were not within AT were excluded from analysis. The locations of intrathalamic injection sites are shown in Figure $2 B$.

Evaluation of seizure response. Seizure analysis was conducted according to three parameters: seizure incidence, seizure severity, and seizure frequency. Seizure incidence is defined as the percentage of animals that exhibit bilateral clonic seizures in an experimental treatment group. Seizure severity is defined as the mean of the maximum seizure scores attained by the animals in a group. Seizure frequency is the number of clonic seizure episodes (score of 3, 4, or 5) occurring within $2 \mathrm{hr}$ of the injection of bicuculline into AT. A two-tailed $t$ test or a repeatedmeasures ANOVA was used for statistical evaluation of seizure frequency; comparisons were made between each experimental treatment group and its corresponding control group.

\section{RESULTS}

Figure 1 shows the autoradiographic localization of 2DG in coronal sections through the brain of a representative rat exhibiting recurrent limbic motor seizures (scores 4 and 5) in response to the microinjection of bicuculline methiodide (118 pmol) into AT. In Figure 1, the injection site can be seen in the left column, middle row (arrow). Several regions (including frontal, piriform, and rhinal cortices) in the hemisphere ipsilateral to the injection exhibit clear hypermetabolism, as evidenced by the high density of $2 \mathrm{DG}$ accumulation. Most regions in the contralateral hemisphere were not distinguishable from control rats (without seizures), with the exception of MD, other midline thalamic nuclei, and substantia nigra, all of which showed marked increases in accumulation of 2DG in both hemispheres. 
A

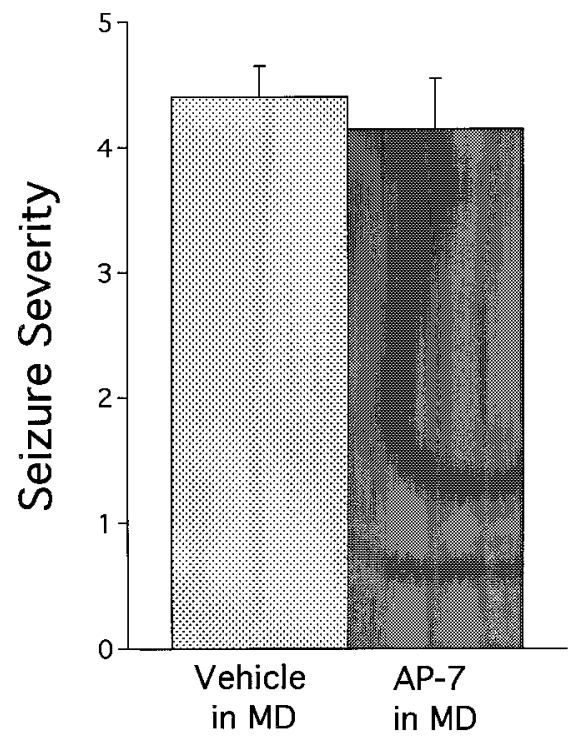

B

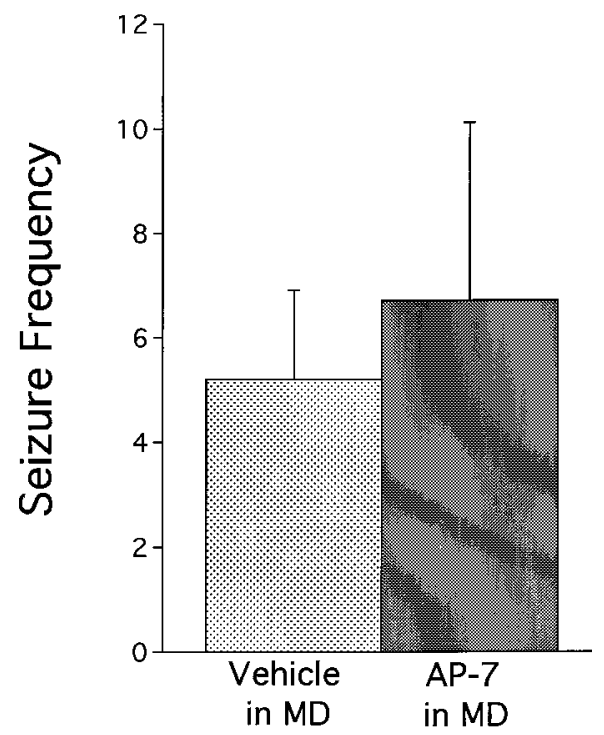

Figure 4. Effect of injection of an NMDA receptor antagonist in MD. AP-7 (500 pmol; $n=7$ ) was unilaterally microinfused into MD 5 min before microinfusion of bicuculline $(118 \mathrm{pmol})$ into the ipsilateral AT. Neither seizure severity nor seizure frequency was modified by AP-7 in MD.

In control conditions (vehicle in MD), the seizures evoked by the application of bicuculline methiodide (118 pmol in AT) consisted of facial and forelimb clonus with rearing (and sometimes loss of balance) in all animals (scores 4 and 5). Figure 2 shows the location of the injection sites. The AMPA receptor antagonist NBQX (500 pmol; $n=9)$, when unilaterally microinf used into $\mathrm{MD}$, protected $100 \%$ of the rats against seizures elicited from AT (Fig. 3). Of the nine animals tested with $\mathrm{NBQX}$ in MD, four animals exhibited no signs of seizure-related activity, whereas the

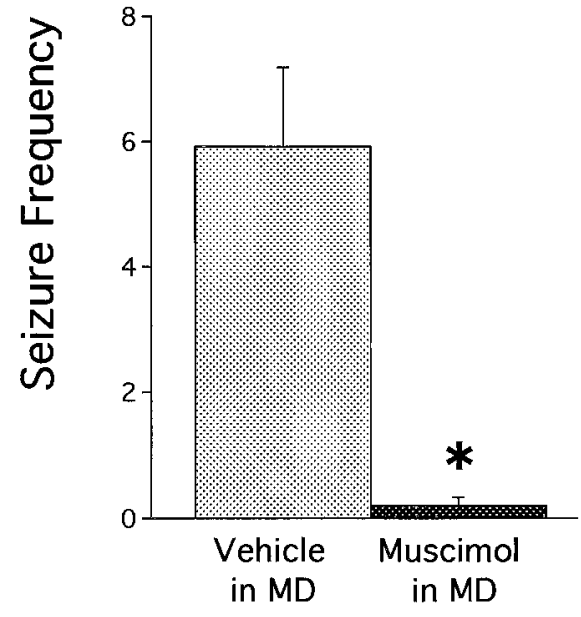

Figure 5. Effect of focal injection of $\mathrm{GABA}_{\mathrm{A}}$ receptor agonist in MD. Muscimol (190 pmol; $n=10$ ) was microinjected into MD 5 min before microinjection of bicuculline $(118 \mathrm{pmol})$ into the ipsilateral AT. Difference from controls, ${ }^{*} p<0.05$ ( $t$ test).

remaining animals exhibited only brief facial twitching (four animals) or myoclonic jerks (one animal). Unilateral focal microinfusion of the NMDA receptor antagonist AP-7 (500 pmol; $n=$ 7) into MD did not significantly alter the seizure response evoked from AT (Fig. 4).

In view of the distinct effects obtained with NBQX and AP-7, some of the animals that received NBQX were subsequently tested with AP-7 (at least $24 \mathrm{hr}$ later), whereas other animals first tested with AP-7 were later tested with NBQX. We found that in the same rats, with application of drugs into the same site on separate occasions, the treatment with NBQX consistently protected against seizures, whereas the AP-7 treatments were without effect.

Unilateral pretreatment of $\mathrm{MD}$ with the $\mathrm{GABA}_{\mathrm{A}}$ receptor agonist muscimol (190 pmol; $n=10) 5$ min before the injection of bicuculline in the ipsilateral AT suppressed the development of limbic seizure activity in 8 of 10 animals. This anticonvulsant effect was evidenced by a significant reduction in seizure severity (for protected animals, the mean seizure score was 0.56 compared with 4.5 in the controls; $38 \%$ of these animals exhibited no seizure-related activity), as well as seizure frequency compared with controls (Fig. 5).

The anticonvulsant effects achieved with muscimol and NBQX were strictly site specific, because no seizure protection was obtained in six rats with injections placed 1-2 mm ventral or lateral to MD (for locations, see Fig. $2 B$ ). Additionally, different injection sites within MD appeared to be equivalent for achieving seizure protection (data not shown). The focal pretreatment of MD alone with the drugs tested did not induce changes in posture, spontaneous behavior, or any other observable abnormalities.

To investigate the role of endogenous GABAergic transmission within MD for controlling limbic motor seizures, vigabatrin (194 nmol) was unilaterally microinf used into MD to elevate endogenous GABA locally by irreversibly inhibiting GABA transaminase activity (Gale and Iadarola, 1980; Casu and Gale, 1981). To evaluate anticonvulsant effects, bicuculline was applied to AT 2.5, 24, and $48 \mathrm{hr}$ after the vigabatrin pretreatment. 
A

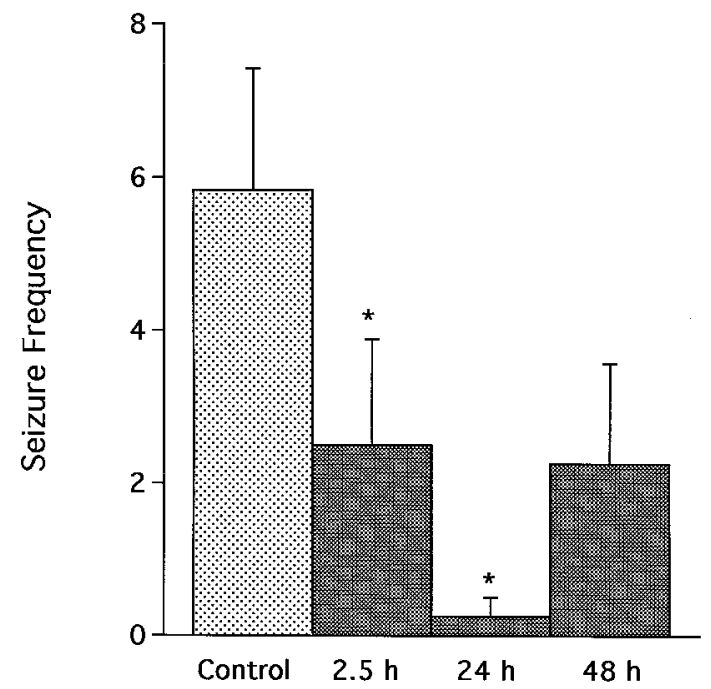

B

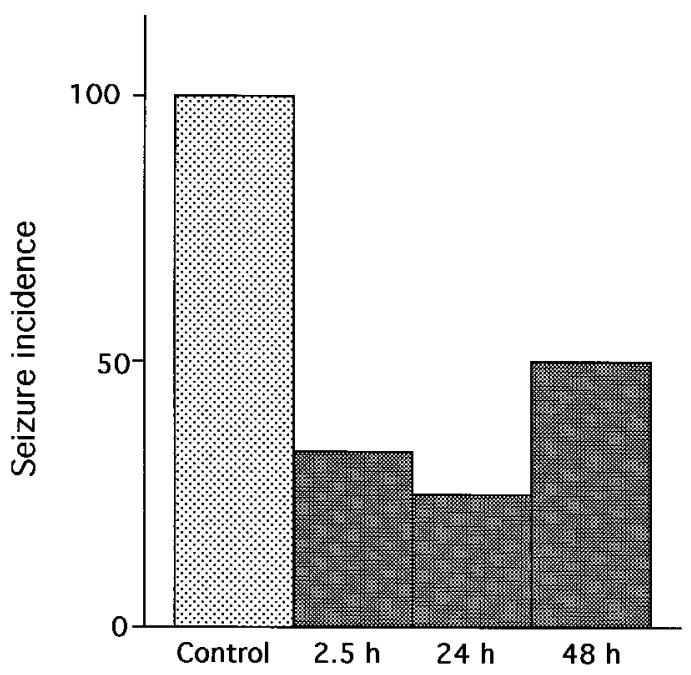

Figure 6. Effect of focal application of a GABA transaminase inhibitor into MD. Vigabatrin (194 nmol) was unilaterally microinfused into MD $2.5,24$, or $48 \mathrm{hr}$ before microinfusion of bicuculline into the ipsilateral AT. Seizure frequency $(A)$ is shown as mean \pm SE for four to six animals per group. Statistical comparisons using ANOVA were performed on the seizure frequency data shown in $A$. Difference from controls, ${ }^{*} p<0.05$. Seizure incidence (percent of rats exhibiting bilateral clonic seizures) is shown in $B$ for the same animals analyzed in $A$.

Pretreatment of MD with a single dose of vigabatrin resulted in significant seizure protection when rats were tested at 2.5 and 24 hr after microinf usion of vigabatrin into MD; recovery from the anticonvulsant effects began by $48 \mathrm{hr}$, as indicated by seizure frequency (Fig. 6A) and the percentage of rats exhibiting seizures at the various time points tested (Fig. 6B).

\section{DISCUSSION}

The results of this study demonstrate that the focal pretreatment of $\mathrm{MD}$ with a $\mathrm{GABA}_{\mathrm{A}}$ receptor agonist or a Glu receptor antagonist interferes with the development of focally evoked limbic motor seizures. These findings suggest that excitatory transmis- sion within MD is required for the development of limbic seizures and that this crucial excitatory transmission is primarily glutamatergic. Moreover, the anticonvulsant effects obtained from MD were site specific, because injections placed 1-2 mm lateral or ventral to MD did not attenuate seizure activity.

In contrast to the effects of the AMPA receptor antagonist NBQX, the NMDA receptor antagonist AP-7 in MD had no effect on seizure activity. This finding suggests that AMPA receptors within MD play a more critical role than NMDA receptors in the transmission involved in the genesis of limbic seizures elicited from piriform cortex.

Patel et al. (1988) reported that the bilateral focal injection of AP-7 into MD, at doses of 10-50 pmol, significantly protected against seizures induced by the systemic administration of pilocarpine, a muscarinic agonist. This finding is in contrast to our results with AP-7 in MD. The differences between the outcomes of the two studies may be a result of differences in the seizure models used and/or the different rat strains used (i.e., Sprague Dawley vs Wistar). Differences between these two rat strains in functional response to subtype-specific Glu agonists have been noted previously (Maggio et al., 1990).

The nonessential role of NMDA receptors in MD for development of AT-evoked seizures stands in contrast to the role of NMDA receptors in AT in the rat. Focal microinfusion of AP-7 $(100 \mathrm{pmol}-1.0 \mathrm{nmol})$ into AT before the microinfusion of bicuculline, carbachol, or kainate was found to prevent the initiation of convulsions from AT (Piredda and Gale, 1986b), indicating that NMDA receptor-mediated transmission in AT is required for triggering seizures from this site in the rat. Thus, the profile of critical neurochemical substrates within AT differs from that in MD.

On the other hand, the pharmacological profile that we have described for MD is similar to that described previously for the posterior piriform cortex, another site critical for the relay of AT-evoked seizures. The posterior piriform cortex is an important target of excitatory output from AT and a key component of the network responsible for the initiation and propagation of seizure activity generated from this site. In posterior piriform cortex, as in MD, blockade of AMPA receptors (with NBQX), but not NMDA receptors (with AP-7), prevents the development of seizures evoked from AT (Halonen et al., 1994).

Anatomical tracing studies have shown that MD is richly connected to several structures that may constitute a network for the propagation of limbic motor seizures elicited from AT. MD receives direct afferents from AT itself (Sahibzada et al., 1992) and from three primary target regions of AT: piriform cortex, entorhinal cortex, and perirhinal cortex (Russchen et al., 1987; Steriade et al., 1987; Gower, 1989; Kuroda et al., 1992). Perirhinal cortex, like MD, is a crucial relay for AT-evoked seizures (Tortorella et al., 1997), raising the possibility that perirhinal cortex and MD may be part of a core seizure-propagating loop activated by AT. Alternatively, MD may regulate multiple neural loops and coordinate their coactivation in parallel. Considerable excitatory connections also exist between MD and basolateral amygdala (Van Vulpen and Verwer, 1989), and this circuitry may contribute to the unusually rapid transfer of kindling between AT and amygdala (McIntyre and Goddard, 1973).

In addition to its associations with limbic structures, MD is linked directly and indirectly (e.g., via prefrontal cortex) with basal ganglia structures that regulate the threshold for limbic motor seizures. Such structures include substantia nigra and entopeduncular nucleus (Kuroda and Price, 1991), which when 
inhibited bilaterally exert anticonvulsant actions in several seizure models (Gale, 1992), and striatum, which suppresses seizures when disinhibited or stimulated (Cavalheiro et al., 1987; Turski et al., 1987). Activation of corticostriatal projections, which in turn stimulate striatal GABAergic projections to substantia nigra, could mediate the influence of MD on seizure susceptibility. However, the fact that we blocked AT seizures with unilateral inhibition of MD argues against this possibility, because the unilateral inhibition of substantia nigra is not sufficient to attenuate AT-evoked seizures (Maggio and Gale, 1989).

The limbic network by which MD influences seizure propagation may share certain crucial components with the network that supports long-term recognition memory. MD, perirhinal cortex, and orbitofrontal cortex have been shown to be critical substrates of recognition memory, based on recording studies (Fahy et al., 1993a,b; Miller and Desimone, 1994) and on the observations that selective bilateral lesions of each of these areas result in profound memory impairment in experimental animals (Aggleton and Mishkin, 1983; Zola-Morgan and Squire, 1985; Bachevalier and Mishkin, 1986; Meunier et al., 1993; Suzuki et al., 1993; Mumby and Pinel, 1994). Furthermore, seizure-induced damage to MD has been correlated with deficits in radial arm maze learning (Persinger et al., 1994). In view of the projections from perirhinal cortex to MD and the reciprocal connections between MD and orbitofrontal cortex, it is likely that MD serves to link these circuits into a coordinated network subserving recognition memory. MD may similarly serve to link the neural loops subserving seizure propagation in frontolimbic networks. Via its connections with amygdala and its ability to regulate prefrontal neurons that project to piriform, perirhinal, and entorhinal cortices, MD may control the extent to which the activity in the network becomes synchronized. Hypersynchrony in this network, as occurs with propagated seizures, would be expected to be incompatible with the more controlled neural signaling important for encoding memory (Fahy et al., 1993a,b). Moreover, suppression of this network, as may occur during postictal or interictal periods, could also impede the mnemonic function of this circuitry. Thus, seizure-evoked acute and/or chronic alterations in MD circuitry may contribute to the memory impairment associated with complex partial seizures.

\section{REFERENCES}

Aggleton JP, Mishkin M (1983) Memory impairments following restricted medial thalamus lesions in monkeys. Exp Brain Res 52:199-209.

Bachevalier J, Mishkin M (1986) Visual recognition memory impairment follows ventromedial but not dorsolateral prefrontal lesions in monkeys. Behav Brain Res 20:249-261.

Carmichael ST, Price JL (1995) Limbic connections of the orbital and medial prefrontal cortex in macaque monkeys. J Comp Neurol 363:615-641.

Casu M, Gale K (1981) Intracerebral injection of gamma vinyl GABA: method for measuring rates of GABA synthesis in specific brain regions in vivo. Life Sci 29:681-688.

Cavalheiro EA, Bortolotto ZA, Turski L (1987) Microinjections of the $\gamma$-aminobutyrate antagonist, bicuculline methiodide, into the caudateputamen prevent amygdala-kindled seizures in rats. Brain Res 411:370-372.

Fahy FL, Riches IP, Brown MN (1993a) Neuronal signals of importance to the performance of visual recognition memory tasks: evidence from recordings of single neurones in the medial thalamus of primates. Prog Brain Res 95:401-416.

Fahy FL, Riches IP, Brown MN (1993b) Neuronal activity related to visual recognition memory: long-term memory and the encoding of recency and familiarity information in the primate anterior and medial inferior temporal and rhinal cortex. Exp Brain Res 96:457-472.
Gale K (1992) Subcortical structures and pathways involved in convulsive seizure generation. J Clin Neurophysiol 9:264-277.

Gale K (1993) Focal trigger zones and pathways of propagation in seizure generation. In: Epilepsy: models, mechanisms, and concepts (Schwartzkroin PA, ed), pp 48-93. Cambridge, UK: Cambridge UP.

Gale K, Dubach M (1993) Localization of area tempestas in the piriform cortex of the monkey. Soc Neurosci Abstr 19:21.

Gale K, Iadarola MJ (1980) Seizure protection and increased nerveterminal GABA: delayed effects of GABA transaminase inhibition. Science 208:288-291.

Giguere M, Goldman-Rakic PS (1988) Mediodorsal nucleus: areal, laminar and tangential distribution of afferents and efferents in the frontal lobe of rhesus monkeys. J Comp Neurol 277:195-213.

Gower EC (1989) Efferent projections from limbic cortex of the temporal pole to the magnocellular medial dorsal nucleus in the rhesus monkey. J Comp Neurol 280:343-358.

Halonen T, Tortorella A, Zrebeet H, Gale K (1994) Posterior piriform cortex and perirhinal cortex relay seizures evoked from the area tempestas: role of excitatory and inhibitory amino acid receptors. Brain Res 652:145-148.

Kuroda M, Price JL (1991) Ultrastructure and synaptic organization of axon terminals from brainstem structures to the mediodorsal nucleus of the rat. J Comp Neurol 313:539-552.

Kuroda M, Murakami K, Kishi K, Price JL (1992) Distribution of the piriform cortical terminals to cells in the central segment of the mediodorsal thalamic nucleus of the rat. Brain Res 595:159-163.

Maggio R, Gale K (1989) Seizures evoked from area tempestas are subject to control by GABA and glutamate receptors in substantia nigra. Exp Neurol 105:184-187.

Maggio R, Liminga U, Gale K (1990) Selective stimulation of kainate but not quisqualate or NMDA receptors in substantia nigra evokes limbic motor seizures. Brain Res 528:223-230.

McIntyre DC, Goddard GV (1973) Transfer, interference and spontaneous recovery of convulsions kindled from the rat amygdala. Electroencephalogr Clin Neurophysiol 35:533-543.

McNamara JO, Bonhaus DW, Shin C (1993) In: Epilepsy: models, mechanisms, and concepts (Schwartzkroin PA, ed), pp 27-47. Cambridge, UK: Cambridge UP.

Meunier M, Bachevalier J, Mishkin M, Murray EA (1993) Effects on visual recognition of combined and separate ablations of the entorhinal and perirhinal cortex in rhesus monkeys. J Neurosci 13:5418-5432.

Miller EK, Desimone R (1994) Parallel neuronal mechanisms for shortterm memory. Science 263:520-522.

Mori H, Mizutani T, Yoshimura M, Yamanouchi H, Shimada H (1992) Unilateral brain damage after prolonged hemiconvulsions in the elderly associated with theophylline administration. J Neurol Neurosurg Psychiatry 55:466-469.

Mumby DG, Pinel JPJ (1994) Rhinal cortex lesions and object recognition in rats. Behav Neurosci 108:11-18.

Patel S, Millan MH, Meldrum BS (1988) Decrease in excitatory transmission within the lateral habenula and the mediodorsal thalamus protects against limbic seizures in rats. Exp Neurol 101:63-74.

Pellegrino LJ, Pellegrino AS, Cushman AJ (1973) A stereotaxic atlas of the rat brain. New York: Plenum.

Persinger M, Bureau Y, Peredery O (1994) Dissociation between conditioned taste aversion and radial arm maze learning following seizureinduced multifocal brain damage: quantitative tests of serial vs. parallel circuit models of memory. Physiol Behav 56:225-235.

Piredda S, Gale K (1985) A crucial epileptogenic site in the deep prepiriform cortex. Nature 317:623-625.

Piredda S, Gale K (1986a) Role of excitatory amino acid transmission in the genesis of seizures elicited from the deep prepiriform cortex. Brain Res 377:205-210.

Piredda S, Gale K (1986b) Anticonvulsant action of 2-amino-7phosphonoheptanoic acid and muscimol in the deep prepiriform cortex. Eur J Pharmacol 120:115-118.

Racine RJ (1972) Modification of seizure activity by electrical stimulation. II. Motor seizure. Electroencephalogr Clin Neurophysiol 32:281-294.

Russchen FT, Amaral DG, Price JL (1987) The afferent input to the magnocellular division of the mediodorsal thalamic nucleus in the monkey, Macaca fascicularis. J Comp Neurol 256:175-210.

Sahibzada N, Chen W, Halonen T, Gale K (1992) Anatomical connections of the area tempestas in the rat. Soc Neurosci Abstr 17:509.

Shimosaka S, So YT, Simon RP (1992) Distribution of HSP72 induction 
and neuronal death following limbic seizures. Neurosci Lett 138:202-206.

Steriade M, Parent A, Pare D, Smith Y (1987) Cholinergic and noncholinergic neurons of cat basal forebrain project to reticular and mediodorsal thalamic nuclei. Brain Res 408:372-376.

Suzuki WA, Zola-Morgan S, Squire LR, Amaral DG (1993) Lesions of the perirhinal and parahippocampal cortices in the monkey produce long-lasting memory impairment in visual and tactual modalities. J Neurosci 13:2430-2451.

Tortorella A, Halonen T, Sahibzada N, Gale K (1997) A crucial role of the $\alpha$-amino-3-hydroxy-5-methylisoxazole-4-propionic acid subtype of glutamate receptors in piriform and perirhinal cortex for the initiation and propagation of limbic motor seizures. J Pharmacol Exper Ther 280:1401-1405.

Turski L, Cavalheiro EA, Sieklucka-Dziuba M, Ikonomidou-Turski C,
Czuczwar SJ, Turski WA (1986) Seizures produced by pilocarpine: neuropathological sequelae and activity of glutamate decarboxylase in the rat forebrain. Brain Res 398:37-48.

Turski L, Meldrum BS, Cavalheiro EA, Calderazzo-Filho LS, Bortolotto ZA, Ikonomidou-Turski C, Turski WA (1987) Paradoxical anticonvulsant activity of the excitatory amino acid $N$-methyl-D-aspartate in the rat caudate-putamen. Proc Natl Acad Sci USA 84:1689-1693.

Van Vulpen EHS, Verwer RWH (1989) Organization of projections from the mediodorsal nucleus of the thalamus to the basolateral complex of the amygdala in the rat. Brain Res 500:389-394.

White LE, Price JL (1993) The functional anatomy of limbic status epilepticus in the rat. I. Patterns of $\left[{ }^{14} \mathrm{C}\right] 2$-deoxyglucose uptake and Fos immunocytochemistry. J Neurosci 13:4787-4809.

Zola-Morgan S, Squire LR (1985) Amnesia in monkeys after lesions of the mediodorsal nucleus of the thalamus. Ann Neurol 17:558-564. 